\title{
Ein Jahr voller Dynamik
}

\author{
Natalie Marty, Karin Würz, Sandra Ziegler
}

EMH-Geschäftsleitung

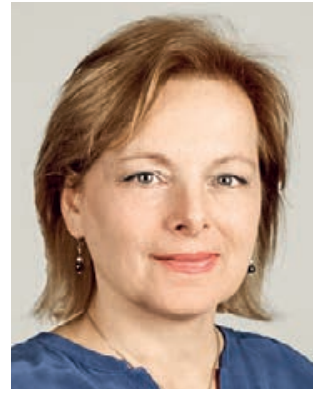

Natalie Marty

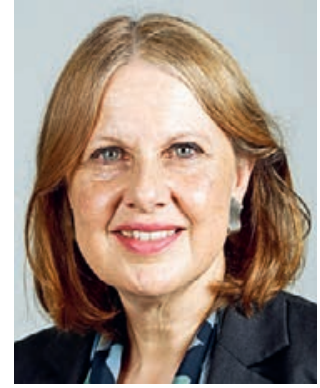

Karin Würz

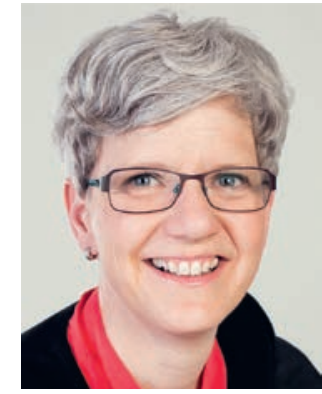

Sandra Ziegler

Wechsel und Veränderungen fordern uns immer wieder aufs Neue heraus. Sie tragen in sich aber auch viel Energie und neue Chancen. In diesem Sinn ist 2019 für das Team der Schweizerischen Ärztezeitung (SÄZ) und EMH ein Jahr voller Dynamik, mit einer Prise Traurigkeit. In diesem Sommer müssen wir unseren Kollegen Bruno Kesseli ziehen lassen, der seit 2005 beim Schweizerischen Ärzteverlag EMH als Chefredaktor der SÄZ und als

Bruno Kesseli hat die SÄZ weiterentwickelt und zu dem gemacht, was sie heute ist: die meistgelesene Zeitschrift für Ärztinnen und Ärzte in der Schweiz.

Mitglied der Geschäftsleitung tätig war. Das fällt uns nicht leicht, hat er doch mit seiner kompetenten, überlegten, aber auch humorvollen Art die SÄZ massgeblich weiterentwickelt und sie zu dem gemacht, was sie heute ist: die meistgelesene Zeitschrift für Ärztinnen und Ärzte in der Schweiz. Wir bedanken uns dafür herzlich und wünschen Bruno alles Gute und viel Erfolg für seine Praxistätigkeit. Vielleicht kann er ja noch den einen oder anderen Gastbeitrag für uns verfassen?

Gleichzeitig begrüssen wir mit Matthias Scholer einen versierten Journalisten und Kommunikator in dieser Funktion, der die SÄZ als Online- und Print-Redaktor sehr gut kennt, aber auch neue Ideen für die gern gelesene Zeitschrift der FMH-Mitglieder mitbringt. Wir sind gespannt auf seine neuen Akzente und freuen uns auf die Zusammenarbeit mit ihm.

Im Hintergrund und darum auch weniger im Rampenlicht haben sich die Rahmenbedingungen für die SÄZ in

diesem Jahr noch zusätzlich verändert. Zum ersten Mal in sieben Jahren werden die Schweizerische Ärztezeitung und das Swiss Medical Forum, beides offizielle Organe der FMH, in diesem Jahr nicht mehr durch einen Beitrag der FMH, das Sockelabonnement, mitfinanziert. EMH ist darum gefordert, diese substanzielle Kürzung im Budget einerseits mit Einsparungen und andererseits mit kreativen Anzeigenangeboten wettzumachen. Wir sind dabei so weit auf gutem Weg in diesem kompetitiven Umfeld, ohne dass wir die Stärken der EMH-Produkte preisgeben: ihre Qualität, die durch die Fachredaktionen und, wo angebracht, durch externes Peer-Review sichergestellt wird.

Daneben will EMH die vielfältigen Chancen der Digitalisierung nutzen. Der technologische Fortschritt bringt neue Perspektiven auch in Form von verbesserten, kundenorientierteren und leserfreundlicheren Angeboten. Die Online-Präsenz ist heutzutage genauso wichtig wie Print. Formate wie Podcasts oder Videos stossen auf grosses Interesse, die Social Media gehören zum Alltagsgeschäft. In diesen Bereichen setzen wir im Moment für alle EMH-Zeitschriften zeitgemässe Konzepte um. Aber auch auf der Produktionsseite werden neue digitale Prozesse zunehmend wichtiger. So evaluiert die SÄZ ein neues Tool zur Einreichung der Artikel, und für alle EMH-Zeitschriften wird aktuell ein neuer Publikationsprozess geprüft. Er soll künftig die Schritte vom Lektorat und von der Übersetzung über das «Gut zum Druck» bis zur Publikation online und im gedruckten Heft effizienter und auch zuverlässiger gestalten.

\section{Der technologische Fortschritt bringt neue Perspektiven auch in Form von verbesserten und kundenorientierteren Angeboten.}

Auch in Zukunft wollen wir die Bedürfnisse der Ärzteschaft und der FMH gezielt abdecken und Produkte anbieten, die Ihnen den ärztlichen Alltag im Spannungsfeld Patienten, Weiterbildung, Fortbildung, Politik und Kommunikation vereinfachen. Daher werden wir in der zweiten Jahreshälfte vermehrt den Input von Fachgesellschaften, Kantonalgesellschaften, aber auch von Ihnen als Leserinnen und Lesern suchen. Bringen Sie sich ein, damit wir Ihnen weiterhin wertvolle Dienstleistungen und lesenswerte Produkte bieten können. 